\title{
Pengembangan PAUD Berbasis Keluarga untuk Meningkatkan Ketrampilan Pengasuhan
}

\author{
Jazariyah dan Maemonah \\ UIN Sunan Kalijaga Yogyakarta \\ Email: jaza.prudent@gmail.com
}

\begin{abstract}
Alignment between early childhood education (PAUD) in the family with the implementation of education in early childhood institutions become a key to optimal development of early childhood. Parents with good parenting skills can be a factor supporting the PAUD institution in achieving its vision and mission. Family-Based Early Childhood where there are some activities involving parents can be a bridge to establish cooperation between parents, educators and institutional managers. For this purpose, this research is conducted in an effort to develop family-based PAUD program, by creating a practical module that can be used by educators and parents. Research results show that the developed product is feasible to be used as an independent learning media that can be used by parents. This is based on the average score of the overall validator in this case media experts, material experts, peers and educators obtained score of 4.53 which is in the category of "very good". Furthermore, based on the pretest results with the value of 23.3 and posttest a number of 32.27 indicates an increase in knowledge of upbringing of 8.9 with a standard gain of 0.75 in the "high" category. Observation of parenting activities shows an average score of 4.6 in $92 \%$ percentage that is categorized as "very high". Based on these results, the modules developed are effective in improving parenting skills.
\end{abstract}

Keywords: module, family based-PAUD, parenting skill. 


\section{PENDAHULUAN}

Pemerintah Indonesia melalui Direktorat Jenderal PAUDNI pada Tahun 2012 telah mengeluarkan Pedoman Penyelenggaraan Pendidikan Anak Usia Dini (PAUD) berbasis keluarga. Pedoman teknis ini dimaksudkan sebagai acuan bagi para pengelola PAUD dalam menyelenggarakan PAUD berbasis keluarga. Terdapat lima kegiatan didalamnya, yaitu Kelompok Pertemuan Orangtua (KPO), Keterlibatan Orangtua di Kelas (KOK), Keterlibatan Orangtua dalam Acara Bersama (KODAB), Hari Konsultasi (HK) dan Kunjungan Rumah (KR). Kegiatan PAUD berbasis keluarga seringkali disebut sebagai kegiatan parenting. Beberapa lembaga yang telah menyelenggarakan kegiatan parenting mengungkapkan kendala yang terjadi saat pelaksanaan kegiatan pertemuan orangtua, salah satunya pedoman teknis yang dikeluarkan Dirjen PAUDNI tentang pelaksanaan PAUD berbasis keluarga masih sangat global sehingga membutuhkan penjabaran yang lebih praktis. Demikian juga kendala waktu serta teknis sehingga penyampaian materi-materi berkaitan dengan pengasuhan tidak tersampaikan secara efektif kepada orangtua anak usiadini. Selain itu sulitnya mengendalikan kondusivitas kegiatan pertemuan orangtua.

Riza Nurahmawati (2016) melakukan sebuah hasil riset pengembangan modul parenting untuk anak usia sekolah dasar, dengan melibatkan 12 orangtua di padukuhan Samirono Yogyakarta. Riset ini menghasilkan sebuah produk berupa modul parenting yang layak untuk digunakan. Penelitian lain berkaitan dengan PAUD berbasis keluarga atau parenting education dilakukan oleh Rudi Himawan (2011). Penelitian ini diarahkan dalam kajian manajemen program parenting. Sebuah penelitian lain yang dilakukan oleh Cathy Bennett, dkk (2013), menyatakan bahwa secara sistematis program parenting berbasis kelompok dapat meningkatkan pengasuhan. Dari hasil penelitian ditemukan adanya perbaikan signifikan sikap orangtua partisipan.Temuan ini mendukung penggunaan program pengasuhan untuk meningkatkan kesejahteraan psikososial jangka pendek orangtua.

Permasalahan di lapangan dalam penyelenggaraan PAUD berbasis keluarga serta berdasarkan hasil penelitian sebelumnya menggerakkan peneliti untuk membuat suatu pengembangan PAUD berbasis keluarga. Peneliti mencoba membuat suatu modul PAUD berbasis keluarga (parenting) yang dapat dijadikan bahan acuan orangtua serta pendidik di 
lembaga PAUD, untuk meningkatkan pengasuhan baik di sekolah maupun di rumah. Harapannya modul ini dapat membantu mewujudkan penyelenggaraan Program PAUD berbasis keluarga menjadi lebih optimal.

\section{PEMBAHASAN}

\section{Modul}

Modul dapat diartikan sebagai sebuah buku yang ditulis dengan tujuan agar peserta didik dapat belajar secara mandiri tanpa atau dengan bimbingan guru. Kamus Besar Bahasa Indonesia mengartikan modul sebagai kegiatan program belajar mengajar yang dapat dipelajari oleh peserta didik dengan bantuan yang minimal dari guru pembimbing, meliputi perencanaan tujuan yang yang akan dicapai secara jelas, penyediaan materi pelajaran, alat yang dibutuhkan serta alat untuk penilaian, mengukur keberhasilan murid dalam penyelesaian pelajaran. Dengan demikian dalam penyelenggaran PAUD berbasis keluarga yang menjadi sasaran adalah orangtua, sehingga modul PAUD berbasis keluarga ini menjadi satu buku yang dapat digunakan secara mandiri oleh orangtua di rumah.

\section{PAUD Berbasis Keluarga}

Program PAUD berbasis keluarga atau Parenting Education bukan diartikan sebagai kelas formal yang harus dijalani orang tua. Melainkan berbagai kegiatan yang dirancang oleh sekolah atau lembaga untuk mengedukasi orang tua agar dapat mengetahui dan menerapkan pendidikan pada anak usia dini. Tidak hanya sebatas memberikan pengetahuan mengenai pendidikan anak namun dapat juga sebagai layanan agar orang tua lebih memahami hak-hak anak yang lain seperti perlindungan anak dan pemenuhan gizi yang baik untuk anak. Kehidupan anak lebih banyak dihabiskan di lingkungan keluarga.Maka besar sekali pengaruh keluarga terhadap pekembangan anak.PAUD berbasis keluarga ini menjadi program yang dapat menjembatani antara sekolah dan orang tua agar memiliki pemahaman yang sejalan dalam pengasuhan, pendidikan dan perlindungan anak. Dengan demikian apa yang menjadi harapan bersama akan terwujud yakni tumbuh dan berkembangnya anak usia dini secara optimal. Menurut Regio Amelia ada tiga tempat yang mempunyai pengaruh besar dan menjadi guru dalam perkembangan kemampuan terhadap anak 
usia dini, yaitu orang tua, guru di sekolah dan lingkungan (Mukhtar Latif, 2014: 260).

\section{Ketrampilan Pengasuhan}

Pengasuhan diartikan juga sebagai sebuah proses tindakan dan interaksi antara orangtua dan anak. Proses dimana kedua belah pihak saling mengubah satu sama lain sampai pada saat anak tumbuh menjadi sosok dewasa (Brooks, 2011: 11). Kegiatan dimana orangtua memberikan bimbingan dan kasih sayang pada anak. Pengasuhan dalam keluarga memiliki dua tugas pokok yaitu, mengembangkan karakter dan kompetensi anak. Pendidikan anak usia dini harus dilaksanakan secara holistik integratif. Stimulasi sejak dini dalam keluarga dapat meningkatkan perkembangan anak.Pengasuhan yang diberikan oleh orangtua kepada anak di rumah merupakan pendidikan untuk anak.Kegiatan pengasuhan ini bukan sekedar merawat dan menjaga seorang anak melainkan mendidik.Melalui pengasuhan orangtua mengantarkan anak melewati tahap demi tahap perkembangan hidupnya (Nugraheni, 2016: 52).

Salah satu teori yang juga diaplikasikan dalam sebuah program untuk peningkatan ketrampilan pengasuhan adalah Triple-P (Positive Parenting Program) yang dipopulerkan oleh Sanders. Dalam program ini menerapkan kemampuan manajemen positif antara orangtua dan anak dalam pengasuhan. Ketrampilan manajemen positif orangtua dengan interaksi anak dapat memunculkan peran positif orangtua, seperti pemberian harapan dan kepercayaan terhadap anak (Plant, K., \& Sanders, M.R., 2007: 362-385).

Dalam penyelenggaraan Tripe-P terdapat lima prinsip yang harus diperhatikan yakni (Mattew R. Sanders: 2011):

1. Ensuring a safe and engaging environment, yaitu menyediakan lingkungan yang aman bagi anak untuk memberinya kesempatan bereksplorasi, bereksperimen dan bermain. Prinsip ini penting untuk mencapai perkembangan yang sehat dan mencegah terjadinya luka dan kecelakaan.

2. Creating a positive learning environment, yaitu orangtua menjalankan peran sebagai guru pertama bagi anak yang harus merespon secara positif dan konstruktif ketika berinteraksi dengan anak (seperti meminta tolong, memberikan informasi, memberi nasehat dan memberi 
perhatian), mendorong anak belajar menyelesaikan masalah mereka sendiri, belajar keterampilan sosial dan komunikasi dengan bahasa yang baik.

3. Using assertive discipline, yang merupakan pengganti bagi disiplin yang menggunakan paksaan dan disiplin praktis yang tidak efektif, seperti teriakan, ancaman, atau menggunakan hukuman secara fisik. Strategi yang digunakan untuk mengubah perilaku dalam disiplin asertif ini meliputi pemilihan aturan dasar untuk situasi tertentu; mendiskusikan aturan dengan anak; memberikan instruksi dan permintaan yang jelas dan tenang sesuai dengan usia anak; mengenalkan konsekuensi logis dan pengabaian terencana.

4. Having realistic expectations, yaitu orangtua mengeksplorasi harapanharapan, kepercayaan dan asumsi-asumsi tentang penyebab perilaku anak, kemudian memilih tujuan yang tepat dan realistis sesuai dengan perkembangan anak.

5. Taking care of oneself as a parents, yaitu mengajarkan keterampilan pengasuhan praktis yang dapat diterapkan oleh kedua orangtua, keterampilan mengeksplorasi keadaan emosional orangtua, dan mendorong orangtua mengembangkan strategi koping untuk mengelola tekanan dan emosi negatif berkaitan dengan pengasuhan, termasuk stres, depresi, kemarahan, dan kecemasan.

Penelitian ini menggunakan pendekatan kualitatif dan kuantitatif dengan jenis peniliatian R\&D (Research and Development).Metode Penelitian dan pengembangan adalah metode penelitian yang digunakan untuk menghasilkan produk tertentu dan menguji keefektifan produk tersebut (Sugiyono, 2016: 407). Penelitian R\&D dilakukan melalui beberapa tahapan menurut Borg dan Gall, yaitu: (1) potensi masalah, (2) pengumpulan data, (3) desain produk, (4) validasi desain, (5) revisi desain, (6) ujicoba produk, (7) revisi produk, (8) uji coba pemakaian, (9) revisi produk (10) produksi massal. Peneliti merumuskan tahap penelitian yang sesuai dengan kebutuhan dan keterbatasan waktu serta dana. Tahap yang ditempuh peneliti hanya pada tahapan ke-7.Ujicoba produk dilakukan melalui dua tahap yakni uji coba terbatas dan uji coba skala luas. 


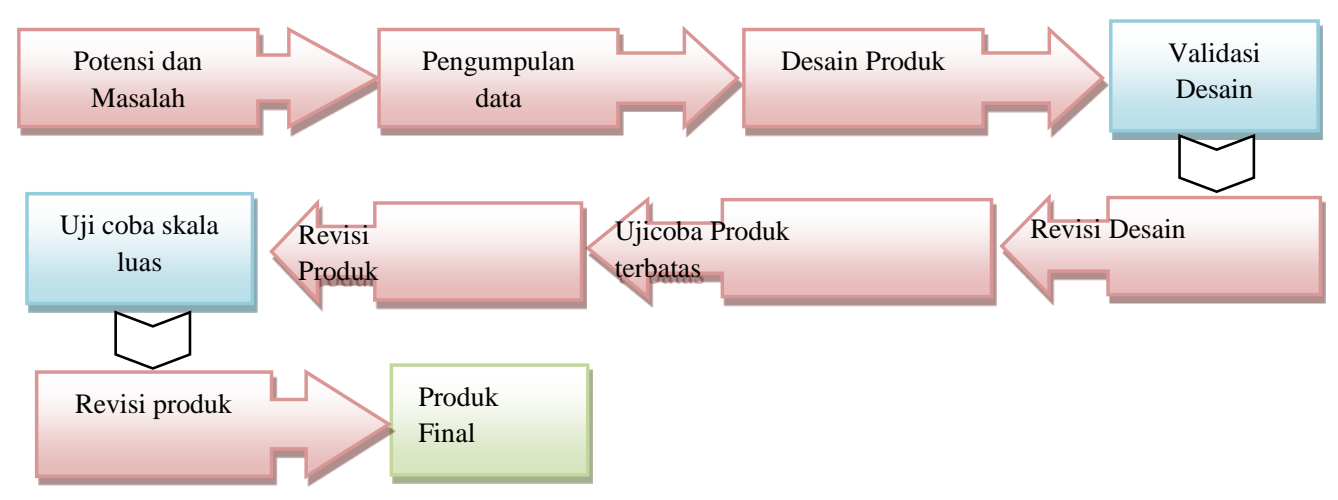

Gambar 1. Langkah-langkah penelitian R\&D yang diterapkan

Langkah-langkah yang digunakan untuk menentukan kriteria kelayakan produk yang telah dikembangkan, sebagai berikut:

1. Data berupa skor penilaian dari ahli media, ahli materi, pendidik dan teman sejawat dirubah menjadi data interval. Dalam angket disediakan lima pilihan untuk memberikan tanggapan terhadap produk yang dikembangkan, yaitu sangat baik (5), baik (4), cukup baik (3), tidak baik (2), dan sangat tidak baik (1).

2. Data yang diperoleh dicari rata-rata skor untuk memperbaiki penilaian terhadap produk yang telah dikembangkan, dengan menggunakan rumus:

$$
\bar{x}_{\mathrm{i}}=\frac{\sum x}{N}
$$

Keterangan:

$$
\begin{array}{ll}
\bar{x}_{i} & =\text { skor rata-rata } \\
\sum x & =\text { jumlah skor } \\
N & =\text { jumlah responden }
\end{array}
$$

3. Untuk memberikan penilaian kelayakan Modul PAUD berbasis keluarga secara keseluruhan yaitu dengan membandingkan nilai rata-rata total skor masing-masing komponen dengan mengkonversikan data kuantitatif ke data kualitatif dengan skala lima dengan kriteria sebagai berikut. 
Tabel 3. Rerata konversi skor

\begin{tabular}{|c|c|c|}
\hline Nilai & Kriteria & Interval Rerata Skor \\
\hline A & Sangat Baik & $4,21>X$ \\
\hline B & Baik & $3,40<X \leq 4,21$ \\
\hline C & Cukup Baik & $2,60<X \leq 3,40$ \\
\hline D & Kurang Baik & $1,79<X \leq 2,60$ \\
\hline E & Sangat Kurang Baik & $X \leq 1,79$ \\
\hline
\end{tabular}

4. Data hasil observasi keterlaksanaan PAUD berbasis keluarga, baik observasi terhadap guru ataupun orangtua dianalisis dengan langkah-langkah sebagai berikut:

a. Berdasarkan penskoran yang dibuat, dihitung jumlah skor berdasarkan hasil masing-masing observer

b. Skor keseluruhan observer dikumulatifkan kemudian dicari rata-ratanya

c. Kemudian data yang diperoleh juga dihitung dengan menggunakan prosentase keidealan yang dihitung dengan menggunakan rumus:

Prosentase Keidealan $=\frac{\text { skor hasil penelitian }}{\text { Skor tertinggi ideal }} \times 100 \%$

d. Skor rata-rata tersebut diprosentase dan dikualifikasi dengan menggunakan kriteria sebagai berikut:

Tabel 4. Kualifikasi Prosentase Skor Hasil Observasi

\begin{tabular}{|c|c|}
\hline Prosentase & Kualifikasi \\
\hline $80,01 \%-100 \%$ & Sangat Tinggi \\
\hline $60,01 \%-80 \%$ & Tinggi \\
\hline $40,01 \%-60 \%$ & Sedang \\
\hline $20,01 \%-40 \%$ & Rendah \\
\hline $0-20 \%$ & Sangat Rendah \\
\hline
\end{tabular}

5. Data pretest-posttest dianalisis untuk mengetahui signifikansi peningkatan ketrampilan pengasuhan orangtua, analisis data yang digunakan dalam hal ini dengan menggunakan nilai gain ternormalisasi $(\mathbf{N}$-gain), gain standar diukur dengan menggunakan rumus:

Gain Standar $=\frac{\text { Skor Posttest }- \text { Skor Pretest }}{\text { Skor Maksimum }- \text { Skor pretest }}$ 
Dalam penelitian ini yang akan dilihat adalah peningkatan pengetahuan pengasuhan orangtua dengan menggunakan modul PAUD Berbasis Keluarga melalui pretest-posttest pada kelas eksperimen. Setelah nilai $\mathrm{N}$-gain diperoleh maka penafsiran dilakukan dengan kriteria sebagai berikut:

Tabel 5. Intrepetasi Nilai N-gain

\begin{tabular}{|c|c|}
\hline Nilai N-gain & Intrepetasi \\
\hline $\mathrm{N}$ - gain $\geq 0,70$ & Tinggi \\
\hline $0,30 \leq \mathrm{N}$-gain $\leq 0,70$ & Sedang \\
\hline $\mathrm{N}$-gain $\leq 0,30$ & Rendah \\
\hline
\end{tabular}

Penelitian dimulai dengan menganalisa kebutuhan lapangan akan modul PAUD berbasis keluarga, yang dilakukan baik dengan cara melakukan pengamatan dan wawancara. Tahap selanjutnya menyusun prototipe modul. Modul awal yang dijadikan prototipe modul PAUD berbasis keluarga terdiri dari:

1. Cover

Tampilan cover prototipe Modul PAUD Berbasis Keluarga

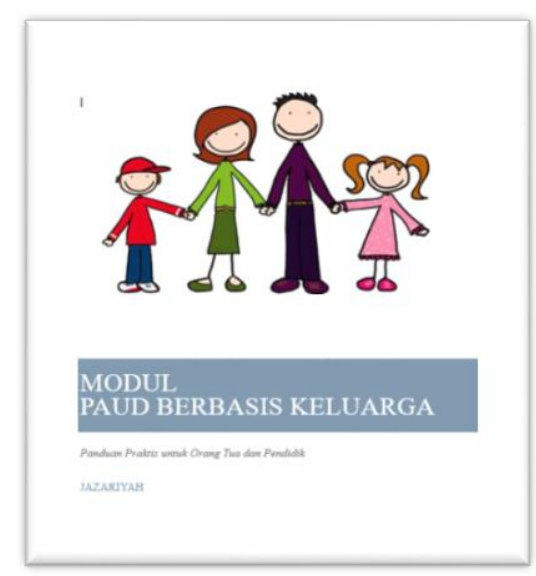

Gambar 2. Desain Cover Prototipe Modul

2. Daftar Isi

3. Kata Pengantar

4. Petunjuk Penggunaan Modul

5. Pendahuluan 
6. Materi (terdiri dari tujuan materi, uraian materi, kolom Ayo Mendata, kolom Tahukah Anda? Dan kolom Ayo Bermain!

7. Daftar Pustaka dan Biografi Penulis

Produk awal yang dikembangkan peneliti diberikan kepada ahli media dan ahli materi untuk divalidasi. Selain itu untuk menguji kelayakan produk awal ini juga divalidasi oleh teman sejawat dan juga pendidik di KB Amanah Bunda. Penilaian dilakukan dengan mengisi angket validasi, dengan rentang nilai 1-5.

Berikut data hasil skor rerata dari total nilai masing-masing validator.

Tabel 6. Data Penilaian Keseluruhan Validator

\begin{tabular}{|c|c|c|c|}
\hline No & Validator & Nilai & Kriteria \\
\hline $\mathbf{1 .}$ & Ahli Materi & 4,38 & Sangat baik \\
\hline $\mathbf{2 .}$ & Ahli Media & 4,14 & Baik \\
\hline $\mathbf{3 .}$ & Teman Sejawat I & 4,76 & Sangat baik \\
\hline $\mathbf{4 .}$ & Teman Sejawat II & 4,57 & Sangat baik \\
\hline $\mathbf{5 .}$ & Pendidik I & 4,38 & Sangat baik \\
\hline $\mathbf{6 .}$ & Pendidik II & 3,95 & Baik \\
\hline & Jumlah & 27,18 & \\
\hline & Rerata & 4,53 & Sangat baik \\
\hline
\end{tabular}

Selain data berupa nilai kuantitatif, saran perbaikan dari validator menjadi pertimbangan penelitia dalam melakukan revisi produk. Berikut adalah rangkuman saran perbaikan yang diberikan validator:

Tabel 7. Saran Perbaikan

\begin{tabular}{|c|c|l|}
\hline No & Ahli & \multicolumn{1}{c|}{ Saran Perbaikan } \\
\hline $\mathbf{1}$ & Ahli Materi & Data grafik, tabel dan gambar harap disertakan sumbernya \\
\hline $\mathbf{2}$ & Ahli Media & $\begin{array}{l}\text { Lembar kegiatan perlu dilengkapi } \\
\text { Gambar ada yang kurang jelas } \\
\text { Cover kurang menarik } \\
\text { Materi ada yang perlu divisualisasikan } \\
\text { Ukuran modul sebaiknya B5 }\end{array}$ \\
\hline $\mathbf{3}$ & Teman Sejawat & $\begin{array}{l}\text { Tulisan pada keterangan gambar kurang jelas } \\
\text { Tampilan pada setiap pergantian materi sebaiknya lebih } \\
\text { berwarna agar bisa menjadi penanda awal materi }\end{array}$ \\
\hline
\end{tabular}

Tahap selanjutnya dilakukan revisi produk awal, berdasarkan hasil validasi dan saran perbaikan yang diberikan oleh para ahli. 
Berikut beberapa revisi yang dilakukan setelah proses validasi, baik oleh ahli media, ahli materi dan teman sejawat. Catatan perbaikan yang disampaikan para validator dijadikan sebagai acuan dalam merevisi produk. Berikut revisi yang dilakukan oleh peneliti:

1. Ukuran kertas modul yang dibuat dirubah dari A4 menjadi B5 sesuai saran dari ahli media.

2. Peneliti memperbaiki desain cover
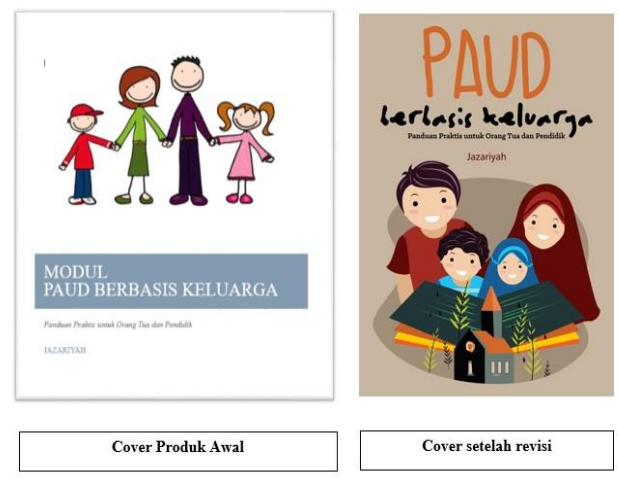

Gambar 3. Display perubahan cover depan

Sementara itu untuk cover belakang produk awal pun mengalami perubahan, jika awalnya bagian belakang cover polos, maka setelah revisi tampak perbandingannya seperti gambar berikut:
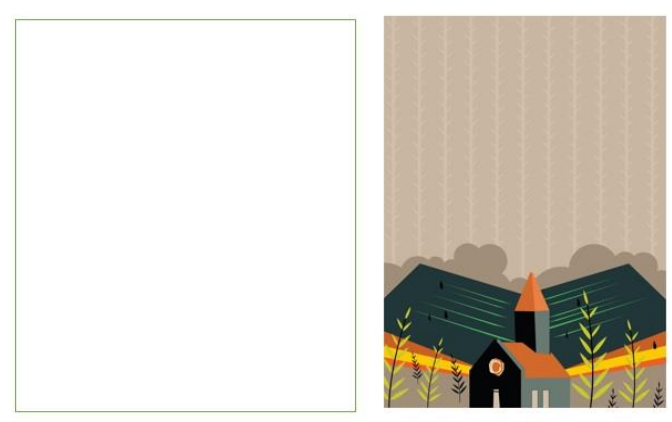

Cover belakang produk awal (polos)

Cover belakang setelah revisi

Gambar 4. Display perubahan cover belakang

3. Revisi beberapa lembar kegiatan Ayo Mendata! danAyo Bermain!Serta merubah ikon pada kolom. 

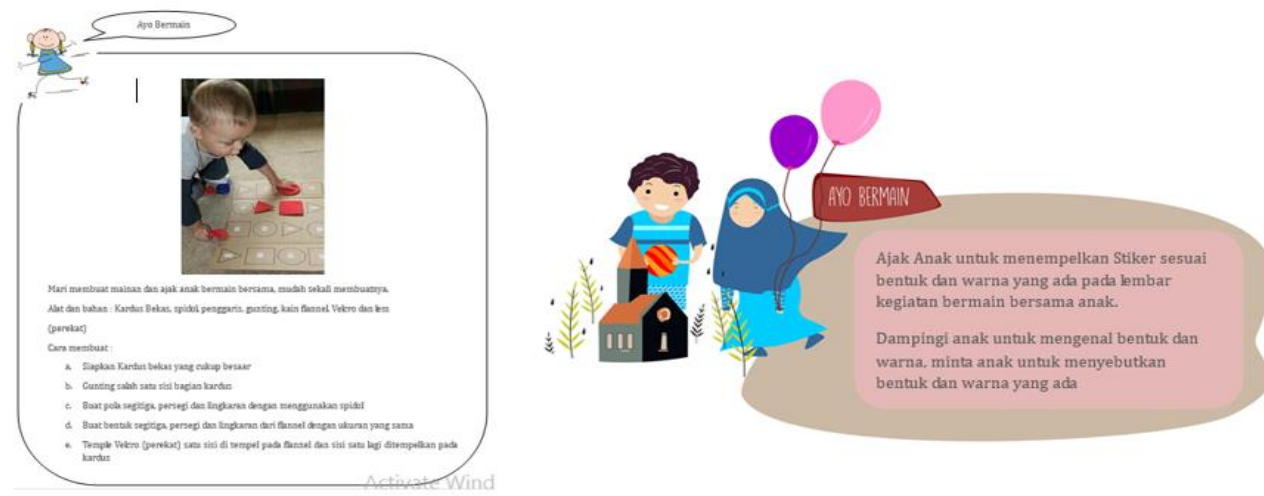

Display Ayo Bermain! Produk Awal

Gambar 5. Display perubahan kolom Ayo Bermain!

Selain merubah rancangan kegiatan main, peneliti juga melakukan perubahan ikon yang diselaraskan dengan desain cover. Kemudian kegiatan Ayo Bermain! Ini dilengkapi dengan lembar kegiatan seperti berikut:

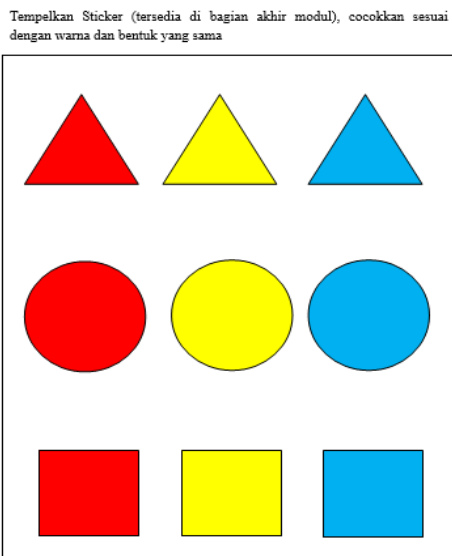

Gambar 6. Contoh lembar kegiatan untuk bermain

4. Visualisasi materi

Menurut ahli media ada beberapa materi yang perlu untuk divisualisasikan. Benntuk poin-poin materi akan lebih mudah dipahami 


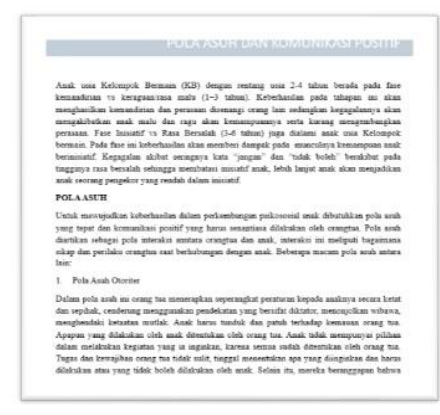

Display uraian materi dalam bentuk paragrap

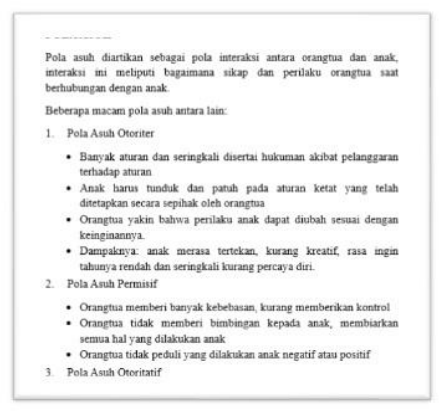

Display uraian materi setelah revisi bentuk poin

Gambar 7. Perubahan uraian materi ke dalam poin-poin

Berdasakan hasil diskusi dan saran perbaikan dengan ahli media, ada materi yang menurut ahli media diperlukan visualisasi.Salah satu contohnya materi tentang tumbuh kembang anak.Berikut hasil revisi peneliti dalam memvisualisasikan materi yang dimaksud.
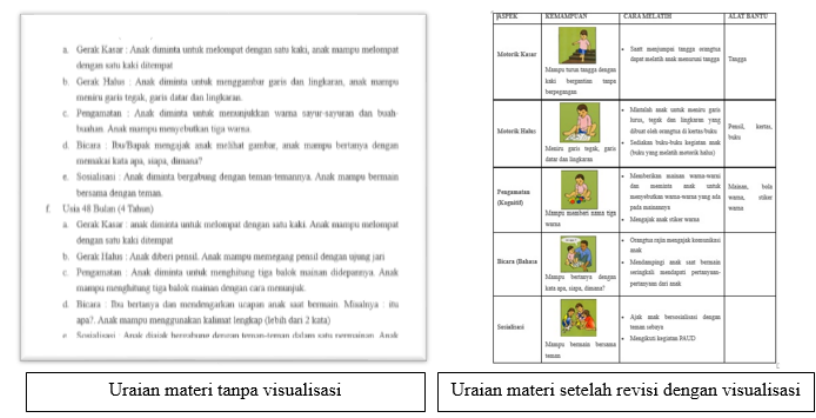

Gambar 8. Perubahan Uraian materi dengan visualisasi

5. Mencantumkan sumber gambar, tabel atau grafik yang terdapat dalam modul

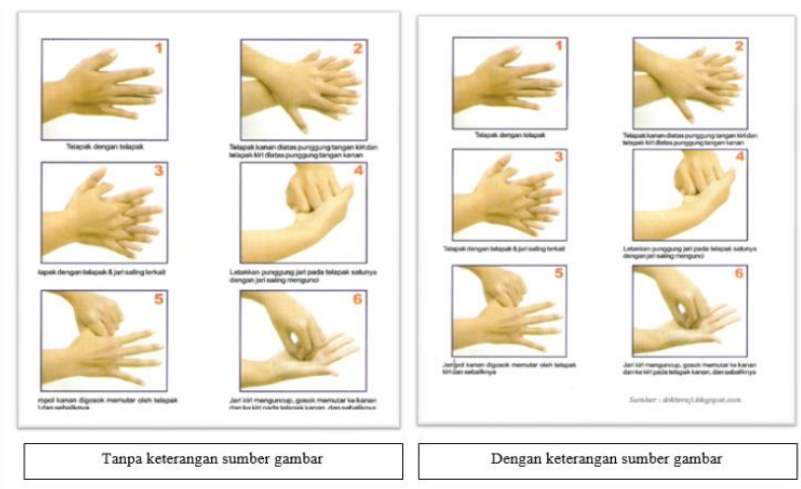

Gambar 9. Pencantuman sumber gambar

12 | AL HIKMAH: INDONESIAN JOURNAL OF EARLY CHILDHOOD ISLAMIC EDUCATION | VOL.1 (1), 2017 
6. Merubah tampilan setiap halaman awal materi agar berbeda dengan halaman lain.

Dari hasil penilaian teman sejawat, disarankan agar setiap awal halaman materi baru dibuat berbeda agar terlihat lebih menarik dan menjadi penanda bergantinya materi baru. Solusi untuk memberikan tanda sebagai awal halaman materi dilakukan peneliti dengan membuat halaman awal setiap materi baru menjadi full colour. Berikut tampilan halaman awal materi sebelum dan setelah direvisi

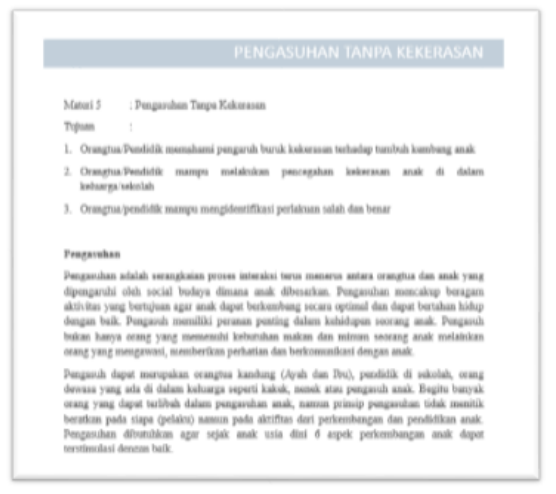

Awal halaman materi sebelum revisi

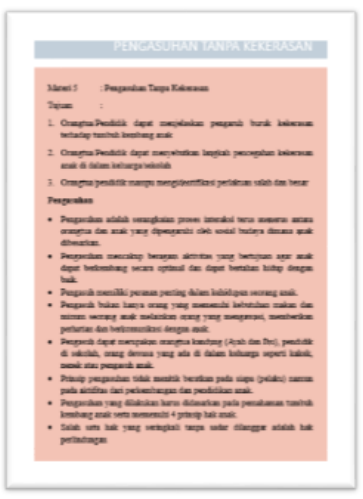

Awal halaman materi setelah revisi

Gambar 10. Perubahan warna halaman awal setiap mater

Pada pengambilan data ujicoba skala kecil hanya diambil 5 orangtua. Proses pengambilan data dilakukan dengan memberikan angket pada orangtua. Berikut rerata hasil respon orangtua pada ujicoba skala kecil.

Tabel 8. Rerata Skor Respon Orangtua

\begin{tabular}{|c|l|c|}
\hline No & \multicolumn{1}{|c|}{ Nama Orangtua } & Rata-rata Skor \\
\hline $\mathbf{1 .}$ & Umi Latifah & 4,45 \\
\hline $\mathbf{2}$. & Eko Lestari & 4,35 \\
\hline $\mathbf{3 .}$ & Kitriningsih & 4,5 \\
\hline $\mathbf{4 .}$ & Ika Murkayati & 4.6 \\
\hline $\mathbf{5 .}$ & Suwarni & 4,8 \\
\hline Rata-rata Skor & $\mathbf{4 , 5 4}$ \\
\hline \multicolumn{2}{|l|}{ Prosentase } & $\mathbf{9 0 , 8} \%$ \\
\hline \multicolumn{2}{|l}{ Kriteria } & Sangat baik \\
\hline
\end{tabular}


Tabel 10. Ketercapaian Peningkatan Pengetahuan Pengasuhan (Data Hasil PretestPosttest)

\begin{tabular}{|c|c|c|c|c|c|c|}
\hline No & Nama & $\begin{array}{c}\text { Skor } \\
\text { Pretest }\end{array}$ & $\begin{array}{c}\text { Skor } \\
\text { Posttest }\end{array}$ & Selisih & $\begin{array}{c}\text { Gain } \\
\text { Standar }\end{array}$ & Interpretasi \\
\hline $\mathbf{1 .}$ & $\begin{array}{c}\text { Orangtua } \\
1\end{array}$ & 27 & 32 & 5 & 0,62 & Sedang \\
\hline $\mathbf{2 .}$ & $\begin{array}{c}\text { Orangtua } \\
2\end{array}$ & 21 & 32 & 11 & 0,78 & Tinggi \\
\hline $\mathbf{3 .}$ & $\begin{array}{c}\text { Orangtua } \\
3\end{array}$ & 25 & 31 & 6 & 0,6 & Sedang \\
\hline $\mathbf{4 .}$ & $\begin{array}{c}\text { Orangtua } \\
4\end{array}$ & 26 & 32 & 6 & 0,67 & Sedang \\
\hline $\mathbf{5 .}$ & $\begin{array}{c}\text { Orangtua } \\
5\end{array}$ & 23 & 33 & 10 & 0,83 & Tinggi \\
\hline & Rata-rata & $\mathbf{2 4 , 4}$ & $\mathbf{3 2}$ & $\mathbf{7 , 6}$ & $\mathbf{0 , 7}$ & Tinggi \\
\hline
\end{tabular}

Untuk mengukur ketrampilan maka peneliti menganalisa aktivitas pengasuhan orangtua pada saat kegiatan KOK dibantu oleh dua observer. Rata-rata skor hasil observasi yang diperoleh dari observer I dan observer II adalah 4,8 yang dalam prosentase dinilai sebannyak $96 \%$, sehingga dikatakan berada pada kategori "sangat tinggi". Berikut data observasi aktivitas pengasuhan yang dilakukan orangtua:

Tabel 11. Data Hasil Observasi Aktivitas Pengasuhan oleh Orangtua dalam Kegiatan Keterlibatan Orangtua di Kelas (KOK) pada Ujicoba Skala Kecil

\begin{tabular}{|c|c|c|c|c|c|}
\hline \multirow[t]{2}{*}{ No } & \multirow[t]{2}{*}{ Aspek yang dinilai } & \multicolumn{2}{|c|}{ Observer } & \multirow{2}{*}{$\begin{array}{l}\text { Rata- } \\
\text { rata }\end{array}$} & \multirow[t]{2}{*}{ Presentase } \\
\hline & & I & II & & \\
\hline 1. & $\begin{array}{l}\text { Memberi kepercayaan dan dukungan pada } \\
\text { anak untuk melakukan kegiatan sendiri }\end{array}$ & 5 & 5 & 5 & $100 \%$ \\
\hline 2. & $\begin{array}{l}\text { Mendorong inisiatif anak untuk memilih } \\
\text { pilihannya sendiri }\end{array}$ & 4 & 5 & 4.5 & $90 \%$ \\
\hline 3. & $\begin{array}{l}\text { Menggunakan kalimat yang positif dalam } \\
\text { mengarahkan anak }\end{array}$ & 4 & 5 & 4.5 & $90 \%$ \\
\hline 4. & Memberikan pujian atas keberhasilan anak & 5 & 4 & 4.5 & $90 \%$ \\
\hline 5. & Bekerjasama dengan baik bersama anak & 5 & 5 & 5 & $100 \%$ \\
\hline 6. & $\begin{array}{l}\text { Mebantu anak tanpa diikuti kata-kata } \\
\text { negatif merendahkan saat mengalami } \\
\text { kesulitan }\end{array}$ & 5 & 4 & 4.5 & $90 \%$ \\
\hline 7. & $\begin{array}{l}\text { Memotivasi anak untuk dapat } \\
\text { menyelesaikan kegiatan }\end{array}$ & 5 & 5 & 5 & $100 \%$ \\
\hline
\end{tabular}




\begin{tabular}{|c|c|c|c|c|c|}
\hline 8. & $\begin{array}{l}\text { Mendampingi anak saat melakukan } \\
\text { kegiatan }\end{array}$ & 5 & 5 & 5 & $100 \%$ \\
\hline 9. & Menunjukkan antusias atas hasil kerja anak & 5 & 5 & 5 & $100 \%$ \\
\hline 10. & $\begin{array}{l}\text { Mendengarkan anak saat mengungkapkan } \\
\text { sesuatu }\end{array}$ & 5 & 5 & 5 & $100 \%$ \\
\hline \multicolumn{4}{|c|}{ Rata-rata } & 4.8 & $96 \%$ \\
\hline & Kategori & & & \multicolumn{2}{|c|}{ Sangat tinggi } \\
\hline
\end{tabular}

Tahapan selanjutnya setelah ujicoba skala kecil dilakukan ujicoba skala besar. Data respon orangtua diperoleh peneliti dari angket yang diberikan kepada 15 responden, sebagai berikut:

Tabel 12. Data Hasil Respon Orangtua pada ujicoba Skala Besar

\begin{tabular}{|c|l|c|c|}
\hline No & \multicolumn{1}{|c|}{ Nama Responden } & Skor & Rata-Rata Skor \\
\hline $\mathbf{1 .}$ & Sujiyanti & 81 & 4.05 \\
\hline $\mathbf{2 .}$ & Eni Rahayu & 86 & 4.3 \\
\hline $\mathbf{3 .}$ & Refiana Rista Dian Pratama & 83 & 4.01 \\
\hline $\mathbf{4 .}$ & Puji Asmani & 85 & 4.25 \\
\hline $\mathbf{5 .}$ & Irfanudin & 83 & 4.15 \\
\hline $\mathbf{6 .}$ & Acik Cahyani & 83 & 4.15 \\
\hline $\mathbf{7 .}$ & Konaah & 81 & 4.05 \\
\hline $\mathbf{8 .}$ & Yuli Intan Tri Buwana T.D & 84 & 4.2 \\
\hline $\mathbf{9 .}$ & Mul Syamsiyah & 85 & 4.25 \\
\hline $\mathbf{1 0 .}$ & Nur Usilah & 87 & 4.35 \\
\hline $\mathbf{1 1 .}$ & Tri Wahyuni & 85 & 4.25 \\
\hline $\mathbf{1 2}$. & Yuni Utami & 87 & 4.35 \\
\hline $\mathbf{1 3 .}$ & Setyo Wahyuningsih & 84 & 4.2 \\
\hline $\mathbf{1 4}$. & Titik Handayani & 81 & 4.05 \\
\hline $\mathbf{1 5 .}$ & Milarsih & 86 & 4.3 \\
\hline Rata-rata Skor & $\mathbf{8 4 . 0 7}$ & $\mathbf{4 . 2}$ \\
\hline Prosentase & & $\mathbf{8 4} \%$ \\
\hline Kategori & & Sangat Baik \\
\hline
\end{tabular}

Tabel 13. Keterlaksanaan Kegiatan PAUD Berbasis Keluarga dengan Modul (Aktivitas Guru pada Kegiatan KOK)

\begin{tabular}{|c|l|c|c|c|}
\hline Tahap & Aspek yang dinilai & \multicolumn{3}{|c|}{ Observer } \\
\cline { 3 - 5 } Kegiatan & & I & II & III \\
\hline $\begin{array}{c}\text { Kegiatan } \\
\text { Awal }\end{array}$ & Guru mengajak siswa dan orangtua berdoa & 1 & 1 & 1 \\
\cline { 2 - 5 } & Guru memberikan motivasi sebelum pembelajaran & 1 & 1 & 1 \\
\hline
\end{tabular}




\begin{tabular}{|c|c|c|c|c|}
\hline & $\begin{array}{l}\text { Guru memberikan apersepsi terhadap materi yang } \\
\text { akan dipelajari }\end{array}$ & 1 & 1 & 1 \\
\hline \multirow[t]{6}{*}{$\begin{array}{l}\text { Kegiatan } \\
\text { Inti }\end{array}$} & $\begin{array}{l}\text { Guru menunjukkan kegiatan dalam modul yang akan } \\
\text { dilaksanakan }\end{array}$ & 1 & 1 & 1 \\
\hline & Guru menjelaskan kegiatan KOK & 1 & 1 & 1 \\
\hline & Guru menyediakan media belajar lainnya & 1 & 1 & 1 \\
\hline & $\begin{array}{l}\text { Guru membimbing orangtua untuk terlibat dalam } \\
\text { kegiatan KOK }\end{array}$ & 1 & 1 & 1 \\
\hline & Guru memantau kegiatan orangtua dan anak didik & 1 & 1 & 1 \\
\hline & $\begin{array}{l}\text { Guru memotivasi orangtua untuk mendampingi anak } \\
\text { dalam mengerjakan tugas tanpa mengambil alih } \\
\text { tugas anak }\end{array}$ & 1 & 1 & 1 \\
\hline \multirow{3}{*}{$\begin{array}{l}\text { Kegiatan } \\
\text { Penutup }\end{array}$} & Guru meluruskan dan membuat kesimpulan & 1 & 1 & 1 \\
\hline & $\begin{array}{l}\text { Guru bersama orangtua melakukan refleksi tentang } \\
\text { manfaat bermain playdoh untuk anak }\end{array}$ & 1 & 1 & 1 \\
\hline & Guru mengajak orangtua dan anak berdoa pulang & 1 & 1 & 1 \\
\hline \multicolumn{2}{|c|}{ Jumlah Skor } & 12 & 12 & 12 \\
\hline \multicolumn{2}{|l|}{ Total Skor } & \multicolumn{3}{|c|}{36} \\
\hline \multicolumn{2}{|c|}{ Rata-rata Skor } & \multicolumn{3}{|c|}{12} \\
\hline \multicolumn{2}{|l|}{ Prosentase } & \multicolumn{3}{|c|}{$100 \%$} \\
\hline \multicolumn{2}{|l|}{ Kriteria } & \multicolumn{3}{|c|}{ Sangat Baik } \\
\hline
\end{tabular}

Hasil pretest ujicoba skala besar sebelum menggunakan modul diperoleh nilai rata-rata sebesar 23, 3 sedangkah untuk posttest diperoleh rata-rata sebesar 32,27 . Berdasarkan data tersebut orangtua mengalami peningkatan pengetahuan pengasuhan sebesar 8,9 dengan gain standar sebesar 0,75 pada kategori "tinggi". Berikut data pretest dan posttest:

Tabel 14. Ketercapaian Peningkatan Pengetahuan Pengasuhan (Data Hasil PretestPosttest)

\begin{tabular}{|c|l|c|c|c|c|c|}
\hline No & \multicolumn{1}{|c|}{ Nama } & $\begin{array}{c}\text { Skor } \\
\text { Pretest }\end{array}$ & $\begin{array}{c}\text { Skor } \\
\text { Posttest }\end{array}$ & Selisih & $\begin{array}{c}\text { Gain } \\
\text { Standar }\end{array}$ & Interpretasi \\
\hline $\mathbf{1 .}$ & Sujiyanti & 21 & 33 & 12 & 0.85 & Tinggi \\
\hline $\mathbf{2 .}$ & Eni Rahayu & 23 & 34 & 11 & 0.92 & Tinggi \\
\hline $\mathbf{3 .}$ & Refiana Rista & 23 & 30 & 7 & 0,58 & Sedang \\
\hline $\mathbf{4 .}$ & Puji Asmani & 24 & 31 & 7 & 0.64 & Sedang \\
\hline $\mathbf{5 .}$ & Irfanudin & 27 & 32 & 5 & 0,62 & Sedang \\
\hline $\mathbf{6 .}$ & Acik Cahyani & 21 & 32 & 11 & 0,78 & Tinggi \\
\hline $\mathbf{7 .}$ & Konaah & 25 & 31 & 6 & 0,6 & Sedang \\
\hline $\mathbf{8 .}$ & Yuli Intan Tri & 26 & 32 & 6 & 0,67 & Sedang \\
\hline $\mathbf{9 .}$ & Mul Syamsiyah & 23 & 33 & 10 & 0,83 & Tinggi \\
\hline
\end{tabular}




\begin{tabular}{|c|l|c|c|c|c|c|}
\hline 10. & Nur Usilah & 21 & 33 & 12 & 0.86 & Tinggi \\
\hline 11. & Tri wahyuni & 21 & 33 & 12 & 0.86 & Tinggi \\
\hline 12. & Yuni Utami & 23 & 32 & 9 & 0.75 & Tinggi \\
\hline 13. & $\begin{array}{l}\text { Setyo } \\
\text { wahyuningsih }\end{array}$ & 24 & 34 & 10 & 0.91 & Tinggi \\
\hline 14. & Titik Handayani & 27 & 31 & 4 & 0.5 & Sedang \\
\hline 15. & Milarsih & 21 & 33 & 12 & 0.86 & Tinggi \\
\hline Rata-Rata & 23.3 & 32.27 & 8.9 & 0.75 & Tinggi \\
\hline
\end{tabular}

Untuk menganalisa ketrampilan orangtua peneliti dibantu observer mengamati aktivitas pengasuhan yang dilakukan orangtua. Berdasarkan pengamatan yang dilakukan terkait aspek kehangatan orangtua dan anak, diperoleh skor rata-rata 4,6 dalam prosentase $92 \%$, sehingga masuk kategori "sangat tinggi". Berikut data selengkapnya:

Tabel 15. Data Hasil Observasi Aktivitas Pengasuhan oleh Orangtua dalam Kegiatan Keterlibatan Orangtua di Kelas (KOK) pada Ujicoba Skala Besar

\begin{tabular}{|c|c|c|c|c|c|}
\hline \multirow[t]{2}{*}{ No } & \multirow[t]{2}{*}{ Aspek yang dinilai } & \multicolumn{2}{|c|}{ Observer } & \multirow{2}{*}{$\begin{array}{l}\text { Rata- } \\
\text { rata }\end{array}$} & \multirow[t]{2}{*}{ Presentase } \\
\hline & & I & II & & \\
\hline 1. & $\begin{array}{l}\text { Memberi kepercayaan dan dukungan pada } \\
\text { anak untuk melakukan kegiatan sendiri }\end{array}$ & 4 & 5 & 4.5 & $90 \%$ \\
\hline 2. & $\begin{array}{l}\text { Mendorong inisiatif anak untuk memilih } \\
\text { pilihannya sendiri }\end{array}$ & 4 & 5 & 4.5 & $90 \%$ \\
\hline 3. & $\begin{array}{l}\text { Menggunakan kalimat yang positif dalam } \\
\text { mengarahkan anak }\end{array}$ & 4 & 5 & 4.5 & $90 \%$ \\
\hline 4. & Memberikan pujian atas keberhasilan anak & 4 & 5 & 4.5 & $90 \%$ \\
\hline 5. & Bekerjasama dengan baik bersama anak & 5 & 5 & 5 & $100 \%$ \\
\hline 6. & $\begin{array}{l}\text { Mebantu anak tanpa diikuti kata-kata } \\
\text { negatif merendahkan saat mengalami } \\
\text { kesulitan }\end{array}$ & 4 & 4 & 4 & $80 \%$ \\
\hline 7. & $\begin{array}{l}\text { Memotivasi anak untuk dapat } \\
\text { menyelesaikan kegiatan }\end{array}$ & 5 & 4 & 4.5 & $90 \%$ \\
\hline 8. & $\begin{array}{l}\text { Mendampingi anak saat melakukan } \\
\text { kegiatan }\end{array}$ & 5 & 5 & 5 & $100 \%$ \\
\hline 9. & Menunjukkan antusias atas hasil kerja anak & 5 & 5 & 5 & $100 \%$ \\
\hline 10. & $\begin{array}{l}\text { Mendengarkan anak saat mengungkapkan } \\
\text { sesuatu }\end{array}$ & 5 & 4 & 4.5 & $90 \%$ \\
\hline \multicolumn{4}{|c|}{ Rata-rata } & 4.6 & $92 \%$ \\
\hline & Kategori & & & \multicolumn{2}{|c|}{ Sangat Tinggi } \\
\hline
\end{tabular}


Tahapan penelitian R\&D selanjutnya adalah melakukan revisi berdasarkan saran perbaikan di lapangan saat ujicoba. Peneliti tidak melakukan pemakaian produk secara luas dan produksi masal, sehingga produk yang direvisi setelah ujicoba menjadi produk akhir. Produk akhir dari penelitian ini berupa modul yang telah melalui proses dan tahapan dalam peneliatian R\&D, yang memiliki karakteristik sebagai berikut:

1. Tampilan cover menarik dan sesuai dengan tema

Cover menarik dapat menjadikan daya tarik tersendiri dari sebuah buku atau modul. Untuk itu berdasarkan saran perbaikan dari ahli media peneliti memvisualisasikan PAUD berbasis keluarga dalam desain cover yang mencerminkan hal tersebut.

2. Tampilan warna yang soft

Tampilan warna dapat memberi stimulus terhadap kemauan membaca seseorang, pilihan warna pastel menjadi pilihan karena tidak terlalu cerah dan cenderung lembut sehingga nyaman dipandang mata.

3. Ikon yang sesuai dengan rubrik

Ikon yang bagus untuk menggambarkan rubrik yang dirancang, menjadi satu kemudahan bagi pembaca untuk memahami maksud penulis.

Adapun kelemahan modul PAUD Berbasis Keluarga ini

1. Masih sebatas membahas tumbuh kembang anak usia Kelompok Bermain

2. Kegiatan main dalam satu materi hanya satu macam, belum beragam.

\section{Efektifitas Modul terhadap Peningkatan Ketrampilan Pengasuhan}

Seperti yang tertera pada tabel 2 tentang aspek dan indikator aktivitas pengasuhan, terdapat 5 aspek. Aspek-aspek tersebut antara lain: aspek kehangatan, kontrol positif, afek positif, proteksi yang tidak berlebihan dan tiadanya hukuman fisik. Modul ini tidak hanya memberikan pengetahuan materi-materi pengasuhan yang harus dimiliki orangtua melainkan juga memberikan contoh kegiatan yang dapat dilakukan orangtua bersama anak. Dalam modul PAUD berbasis keluarga ini setiap materi diberikan rubrik ayo bermain! Tujuan kegiatan ini 
utamanya adalah untuk membangun kehangatan antara orangtua dan anak.Mendorong orangtua untuk memberikan penghargaan, dukungan dan responsif terhadap anak. Ketiga indikator kehangatan tersebut mampu membentuk sikap mandiri dan inisiatif anak yang berusaha dibangun pada usia kelompok bermain.

Usia yang dalam perkembangan psikososial seperti tertera pada tabel 1, mengalami fase krisis kemandirian Vs rasa malu, inisiatif Vs rasa bersalah. Dalam rangka mewujudkan hasil positif agar anak-anak tidak mengalami hasil yang sebaliknya, maka dibutuhkan stimulasi baik dari pendidik dan utamanya orangtua untuk mencapai tahapan perkembangan tersebut. Maka dalam rancangan kegiatan main dalam rubrik ayo bermain! Peneliti berusaha mendesain kegiatan main yang memberikan kesempatan bagi orangtua untuk membangun kehangatan bersama anak.Memberikan penghargaan atas hasil karya anak sehingga menumbuhkan percaya diri dan kemandirian.Memberikan dukungan serta responsif pada anak, yang dapat memberikan hasil positif pada perkembangan anak. Dari data respon orangtua, hasil pretest dan posttes serta observasi menunjukkan bahwa modul ini berada pada kategori sangat baik serta gain standar pada kategori tinggi.Sehingga dapat diambil kesimpulan bahwa Modul PAUD berbasis keluarga ini berhasil meningkatkan ketrampilan pengasuhan orangtua.

\section{SIMPULAN}

Berdasarkan analisa data dan pembahasan yang dilakukan dapat diambil kesimpulan bahwa modul PAUD berbasis keluarga yang dikembangkan berdasarkan analisa data validasi baik ahli materi, ahli media, teman sejawat dan pendidik berada pada kategori "sangat baik". Hasil respon orangtua terhadap Modul PAUD berbasis keluarga dalam uji skala kecil dan besar sama-sama menunjukkan kategori sangat tinggi, sehingga dapat disimpulkan modul ini layak untuk digunakan dalam penerapan PAUD berbasis keluarga. Hasil pretest dan posttes berdasarkan analisa data penelitian menunjukkan adanya peningkatan pengetahuan ketrampilan pengasuhan yang tinggi dengan nilai pretest rata-rata 23,3 sedangkan posttest rata-rata sejumlah 32,27 sehingga mengalami peningkatan sebannyak 8,9 dengan gain standar 0,75 pada ujicoba skala besar. Nilai gain standar tersebut masuk dalam kategori "tinggi". Observasi 
aktivitas pengasuhan oleh orangtua dengan menggunakan modul PAUD berbasis keluarga juga mencapai skor rata-rata 4,6 dalam prosentase $92 \%$ sehingga masuk dalam kategori sangat tinggi. Dengan demikian penggunaan Modul PAUD berbasis keluarga dianggap efektif dalam meningkatkan ketrampilan pengasuhan orangtua.

\section{DAFTAR PUSTAKA}

Abdul Hafizh Suwaid, Muhammad Nur, Prophetic Parenting Cara Nabi Mendidik Anak, Yogyakarta: Pro-U Media, 2010

Baumrind, Current Pattern of Parental Auothority: Developmental Pshycology Monographs, America: American Psychological Association, 1971

Brierley, John, Give Me a Child Until He is Seven; Brain Studies \& Early Childhood Education, London: The Falmer Press, 1994

Brooks Jane, The Process of Parenting (Alih Bahasa: Rahmat Fajar), Yogyakarta: Pustaka Pelajar

Catty, Bennett, et.al., Group-based Parenting Program for improving dan psychosocial functioning: A systematic Review. Journal of the Society for Social Work and Research, vol. 4 Issue 4, 31 Desember 2013.

Daryanto, Menyusun Modul: Bahan Ajar untuk Pesiapan Guru dalam Mengajar, Yogyakarta: Gava Media, 2013

Depdiknas, Pedoman Penulisan Modul, Jakarta: Direktorat LPP, Ditjend Dikdasmen, Depdiknas: 2003

Dewi S, Anita Chandra dkk, Desain Pengembangan Anak Usia Dini Holistik Integratif PAUD Non Formal (Penelitian Research and Development di POS PAUD Mutiara Keluarahan Lamper Lor Kecamatan Semarang Selatan), Jurnal Penelitian PAUDI Volume 2 No.1, Mei 2013.

Diadha, Rahminur, Keterlibatan Orangtua dalam Pendidikan Anak Usia Dini di Taman Kanak-Kanak. Edusentris; Jurnal Pendidikan dan Pengajaran, Vol. 2 No. 1, Maret 2015

Dirjen PAUDNI, Pedoman Penyelenggaraan Pendidikan Anak Usia Dini Berbasis Keluarga, (Jakarta: Dirjen PAUDNI, 2012), hlm. 9-10 
Erikson, Erik H, Childhood and Society, London: Paladin Grafton Books, 1987

Fauzi, Nasrul, Pengembangan Modul Pembelajaran IPA Berbasis Nilai-Nlai Humanis John $P$ Miller untuk Meningkatkan Kepekaan Sosial Peserta Didik MI/SD Kelas IV, Thesis, (Yogyakarta, UIN Sunan Kalijaga: 2015), hlm. 34

Fuad Abdul Baqi, Muhammad, Shahih Muslim Jilid 4, cetakan 1, (penerjemah: Rohimi Ghufron), Jakarta: Pustaka Assunah, 2010

Gall, Meredith D., Joyce P. Gall \& Walter R. Borg, Educational Research an Introduction Seventh Edition, USA; Pearson Education, 2003

Gottman, John dan Joan DeClaire, Kiat-Kiat membersarkan Anak yang Memiliki Kecerdasan Emosional, (Jakarta: Gramedia, 2003), hlm. 40-43

Hariawan, Rudi., Manajemen Program Parenting Pada PAUD Unggulan Nasional (Studi Multi Situs pada PAUD Anak Saleh dan PAUD Firdaus di Malang Raya, Tesis, Program Pascasarjana Universitas Negeri Malang, 2011

Hurlock, Elizabeth B., Perkembangan Anak, Jilid 2, Jakarta: Erlangga, 1978

Idi, Abdullah \& Safarina Hd, Etika Pendidikan; Keluarga, Sekolah dan Masyarakat, (Jakarta: Grafindo, 2016), hlm. 138

Ismail, Andang, Education Games, Yogyakarta: Pro-U Media, 2009

Izzati, Rita Eka, Pengasuhan dan Perkembangan Anak, http://staff.uny.ac.id/sites/default/files/lain-lain/dr-ritaeka-izzaty-spsi-msi/PENGASUHAN.pdf di akses Tanggal 8 januari 2017

Latif, Mukhtar, dkk, Orientasi Baru Pendidikan Anak Usia Dini Teori dan Aplikasi, Jakarta: Kencana, 2014

Lavine, Janet, Know Your Parenting Personality; How to Use Enneagram to Become the Best Parent You Can Be, New Jersey: John weley \& Sons, 2003

Mahmudi, Manajemen Kinerja Sektor Publik, Yogyakarta: AMP YKPN, 2007 
Mansur, Pendidikan Anak Usia Dini dalam Islam, Yogyakarta: Pustaka Pelajar, 2011

Mulyati, Yeti, "Pokok-Pokok Pikiran tentang Penulisan Modul Bahan Ajar dan Diklat", Paper dipresentasikan dalam acara Pendidikan dan Pelatihan Bahasa Indonesia dan Bahasa Inggris bagi Widyaiswara BPD, PPPG dan Instruktur, di PPPG Jakarta Selatan, tanggal 15-25 Juni 2002,

Mustari, Mohamad, Manajemen Pendidikan, Jakarta: Grafindo, 2015

Nolte, Dorothy Law dan Rachel Harris, Anak-Anak Belajar dari Kehidupannya Nilai-Nilai Parenting Klasik Dunia, Yogyakarta: Pustaka Pelajar, 2016

Nugraheni. Shohaiva, "Persepsi dan Partisipasi Orangtua terhadap Lembaga PAUD Sebagai Tempat Pendidikan Pada Anak Usia Dini (Studi pada orangtua di desa Tragung, Kecamatan, Kecamatan kandeman, Kabupaten Semarang", Journal of Non Formal Education and Community Empowerment Volume 3 No. 2 Tahun 2016

Nurrahmawati, Riza, Pengembangan Modul Parenting Anak Usia Sekolah Dasar, Skripsi, Universitas Negeri Yogyakarta, 2016

Plant, K., \& Sanders, M.R. "Reducing Problem Behaviour during Care Giving in Families of Pre school-age Children with Developmental Disabilities".Journal Research In Develomental Disabilities. Vol 28, Tahun 2007

Prastowo, Andi, Panduan Kreatif Membuat Bahan Ajar Inovatif, Menciptakan Metode Pembelajaran yang Menarik dan Menyenangkan, Yogyakarta: Diva Press, 2011

Purnama, Sigit, Materi-Materi Parenting Education menurut Pemikiran Munif Chatib, Laporan Penelitian BOPTN, Yogyakarta: UIN Sunana Kalijaga, 2013, hIm. 27

Rahman, Hibana S., Konsep Dasar Pendidikan Anak Usia Dini, Yogyakarta: PGTKI dan Penerbit Glagah, 2002

Rakhmawati, Istina, Peran Keluarga dalam Pengasuhan Anak, Konseling Religi: Jurnal Bimbingan Konseling Islam volume 6 No. 1, Juni 2015. 
Rifa Hidayah, Psikologi Pengasuhan Anak, Malang: UINMalang Press, 2009

Rizkita, Amanda, Implementasi Program Parenting untuk Meningkatkan Kapasitas Pengasuhan Orangtua di KOBER Bunga Nusantara (Studi Deskriptif pada PKBM Jayagiri Kecamatan Lembang, Skripsi, Universitas Pendidikan Indonesia, 2014

Sanders, M.R., Parenting Intervention of Complex Problems, Paper Presentation, university of Quenssland, October 2011.

Siswoyo, Rasdi Eko, dkk, "Potensi Keluarga dalam Pendidikan Holistik Berbasis Karakter Pada Anak Usia Dini”, Fakultas IImu Pendidikan Universitas Negeri Semarang

Suciati, Komunikasi Interpersonal Sebuah Tinjauan Psikologis dan Perspektif Islam, Yogyakarta: Buku Litera, 2015

Sudijono, Anas, Pengantar Evaluasi Pendidikan, Jakarta: Raja Grafindo, 2011

Sudjana, Nana \& Ahmad Rivai, Teknologi Pengajaran, Cet. Ke4, Bandung: Sinar Baru Algesindo, 2004

Sugiyono, Metode Penelitian Pendidikan Pendekatan kuantitatif, Kualitatif dan R\&D, Bandung: Alfabeta, 2016

Sukrisno, Dedy, Efektifitas Pelaksanaan Parenting Education di PAUD Taram SKB Kabupaten Trenggalek, ejournal.unesa.ac.id/article/6917/14/article.pd diakses pada tanggal 22 Januari 2016

Suyadi \& Maulidya Ulfah, Konsep Dasar PAUD, Bandung: Rosdakarya, 2016

Syam, Nia Kurniati dkk, Pelatihan Parenting (Komunikasi Pengasuhan Anak Usia dini) Bagi Orangtua, Pendidik dan Kader PKK di Desa Nagrog Cicalengka, Prosiding Seminar Nasional Penelitian dan PKM Social, Ekonomi dan Humaniora, Universitas Islam Bandung, 2015

Tim Penyusun, Bahan Penyuluhan Bina Keluarga Balita (BKB); Pengasuhan dan Pembinaan Tumbuh Kembang Anak, Klaten: Pemberdayaan Perempuan dan Keluarga Berencana, 2010

Tim Penyusun, Pedoman Pengembangan Pembelajaran (Kurikulum) dan Perangkat Bahan AjarPAUD HI, Semarang: Dinas Pendidikan Jawa Tengah, 2014 
JAZARIYAH DAN MAEMONAH

Ummi Shofi, Agar Cahaya Mata Makin Bersinar: Kiat-Kiat Mendidik Ala Rasulullah, Surakarta: Afra Publishing, 2007

Unicef, Materi Peserta Pelatihan Dasar Holistik Integratif, 2015 Widoyoko, Eko Putro, Evaluasi Program Pembelajaran; Panduan Praktis Bagi Pendidik dan Calon Pendidik, Yogyakarta: Pustaka Pelajar, 2009

Wiyani, Novan Ardy \& Barnawi, Format PAUD, Yogyakarta: ArRuzzmedia, 2012 